from Uttarakhand ${ }^{11}$, and help industries to reduce labour cost required for the cleaning of HRDs. Proper supply chain management is also crucial for sustenance of the sector and may be strengthened by establishing Farmer Producer Organizations/Farmer Producer Companies and developing marketing infrastructure. Primary processing and value addition along with strengthening of marketing network should be considered for regular supply of quality HRDs to industries ${ }^{2}$. This can be achieved by establishing new and strengthening existing herbal collection and retail/wholesale outlets (mandis) with post-harvest processing and testing facilities. Linkages between farmers and buyers, and buy-back interventions through on-line virtual platforms such as e-charak and e-NAM are other measures that can be taken into consideration. In conclusion, a comprehensive national-level policy/ strategy is needed to address various issues pertaining to the cultivation, collection, processing, harvesting, quality and marketing of HRDs.

1. Goraya, G. S. and Ved, D. K., Medicinal Plants in India: An Assessment of their Demand and Supply, Government of India (GoI), Dehradun, 2017, pp. 1-430.

2. Bisht, V. K. et al., Post-harvest techniques for medicinal and aromatic plants. In Ethnobotany and Medicinal Plants (eds Bharti, P. K. and Chauhan, A.), Ancient Publishing House, Delhi, 2013, pp. $28-45$.

3. Ayurvedic Pharmacopoeia of India, Department of AYUSH, Ministry of Health and Family Welfare (MoHFW), GoI, 2008, vols I-IX.

4. Srirama, R. et al., Assessing species admixtures in raw drugs trade of Phyllanthus, a hepatoproctective plant using molecular tools. J. Ethnopharmacol., 2010, 130, 208-215.

5. Seethapathy, G. S. et al., Assessing product adulteration in natural health products for laxative yielding plants, Cassia, Senna and Chamaecrista, in southern India using DNA barcoding. Int. J. Legal Med., 2015, 129(4), 693-700.

6. Santosh, K. J. U. et al., DNA barcoding to assess species adulteration in raw drug trade of 'Bala' (genus: Sida L.). Biochem. Syst. Ecol., 2015, 61, 501-509.

7. Wallace, L. J. et al., DNA barcodes for everyday life: routine authentication of natural health products. Food Res. Int., 2012, 49, 446-452.

8. Gilbert, N., Herbal medicine rule book: can Western guidelines govern eastern herbal traditions? Nature, 2011, 480, S98-S99.

9. WHO, Guidelines on Good Agricultural and Collection Practices for Medicinal Plants, World Health Organization, Geneva, 2003.

10. NMPB, Guidelines on Good Field Collection Practices for Indian Medicinal Plants, National Medicinal Plants Board, MoHFW, GoI, 2009.

11. Kuniyal, C. P. and Bisht, V. K., Impact of facilitation on marketing of tejpat (Cinnamomum tamala) from non-forest areas in Uttarakhand, Western Himalaya. Natl. Acad. Sci. Lett., 2015, 38(1), 91-92.

Received 10 July 2020; revised accepted 19 September 2020

doi: $10.18520 / \mathrm{cs} / \mathrm{v} 119 / \mathrm{i} 10 / 1699-1702$

\section{Examining the trapping efficiency of different coloured light emitting diodes in combination with the host plant for monitoring and managing banana weevils}

\author{
Mani Kannan, Balakrishnan Padmanaban*, \\ Kammatterikunnu Ashif, Narayanan Baskar and \\ Subbaraya Uma
}

ICAR-National Research Centre for Banana, Thayanur, Thogamalai Road, Tiruchirappalli 620 102, India

\begin{abstract}
Light emitting diode (LED)-based insect monitoring approach is drawing the attention of researchers. In the present study, we evaluated the insect pest response to four different coloured LEDs (blue, green, red and warm white or yellow) in the laboratory (darkroom) and in field conditions. The field studies indicated that Odoiporus longicollis is attracted to blue LED with a longitudinal split banana stem trap (LSBST), with an average of $7 \pm 1$ weevils per trap, compared to other LEDs and LSBST. However, the corm weevil was not attracted to the traps significantly. To confirm the weevil response to LED trap, an experiment was performed in the laboratory. Interestingly, the laboratory experiment indicated a higher attraction of $O$. longicollis towards blue LED + LSBST with $63 \pm 5.77 \%$ in male and $53.33 \pm 5.77 \%$ in female, and of Cosmopolites sordidus with $43.33 \pm 5.77 \%$ in both male and female when compared with other traps. The overall results suggest that blue LED can be used as a light trap for monitoring as well as the mass trapping of banana weevils in the garden.
\end{abstract}

Keywords: Banana weevils, integrated pest management, light-emitting diode, trapping efficiency.

BANANA is one of the most important and preferred dietary fruit crops, but its production remains insufficient for the rapidly growing population ${ }^{1}$. Banana weevils (Cosmopolites sordidus and Odoiporous longicollis) affect the growth and yield of banana cultivars like Nendran, Poovan $(\mathrm{AAB})$, Karpuravalli and Monthan $(\mathrm{ABB})^{2-4}$. C. sordidus and $O$. longicollis adults lay their eggs on the outer leaf sheath and corm respectively, and live inside the freshly cut pseudostem or dead plants. The larvae of $O$. longicollis feed on the pseudostem by making a tunnel which leads to stem break and the plant is damaged. $C$. sordidus weevils feed on corm and prevent sucker or mate formation, which results in the plant producing small or immature bunches. These weevils cause production loss ranging from $10 \%$ to $90 \%$ (refs $2-4$ ). Since adult weevils and grubs live within the pseudostem, it is

\footnotetext{
*For correspondence. (e-mail: bpadmanabannrcb@gmail.com)
} 
difficult to manage them with pesticides; they are resistant to insecticides too. Moreover, pesticides are toxic to natural ecosystem ${ }^{5}$.

To minimize pesticide usage, there are many technologies like coloured light, yellow pan and sticky traps used for monitoring and mass trapping the insect pest in the field for a long time ${ }^{6-10}$. The light-based insect traps were developed using visual cues and phototactic behaviour of insects $^{11,12}$. Phototaxis is a kind of insect behaviour where it can sense the light from a broad to narrow range such as ultraviolet (UV), violet and dark blue with less intensity $^{13-16}$. Green et al. $^{7}$ suggested that light emitting diode (LED) can be used to replace the more power-demanding traditional light traps. It has been proved that LEDs reduced pesticide usage (25-65\%) and suppress pest populations in the garden ${ }^{17}$. Further, the LED technology is easy to execute because it has wavelengths which are insect-specific, and is portable with an extended lifetime ${ }^{17}$. LED powered by solar energy is an effective alternative to the conventional electric light traps; it is economically and environmentally advantageous. LED traps have been extensively used to control insect pests like [Liriomyza trifolii, Trialeurodes vaporariorum, Lasioderma serricorne (F.) and Stegobium panicellum (L)] which are attracted to UV and blue LED ${ }^{18-21}$. The present study was aimed to monitor the banana stem and corm weevil response to LED traps in combination with the host plant under field and laboratory conditions.

In order to evaluate the traps under field conditions, two banana gardens endemic to banana weevils, one each from Thirukkattupalli and Tiruppanandal, Thanjavur district, Tamil Nadu, were selected for the study. The garden had cultivars of Poovan either with Karpuravalli or Monthan. The pre-surveillance of pest distribution and damage symptoms like bores and jelly exudation in the pseudostem, number of insect pests and their population were recorded in the selected field. Four different coloured LEDs with different wavelength, viz. $400 \pm 460,680 \pm$ $700,530 \pm 550$ and $395 \pm 530 \mathrm{~nm}$ for blue, red, green and warm white (produces a yellow hue) respectively, with a DC $12 \mathrm{~V}$ adapter were used. We used four LED traps in each colour per acre. Each trap was prepared using $1 \mathrm{~m}$ LED strip rolled on a $30 \mathrm{~cm}$ long 2" PVC pipe.

Initially, five treatments (T1, blue LED + longitudinal split banana stem trap (LSBST); T2, green LED + LSBST; L3, red LED + LSBST; L4, LSBS/corm trap alone, and T5, LED alone from each colour) were deployed with a $30 \mathrm{~m}$ distance between each trap under field conditions. Later, blue and warm white or yellow hue LEDs and LSBS/corm trap were repeated for further confirmation. Lighting was scheduled from 8.00 p.m. to 6.00 a.m. The field experiment was replicated thrice. The attracted insect pests in the banana garden were collected and stored in a $15 \mathrm{ml}$ perforated plastic container with the host. The collected insects were brought to the laboratory for further studies.
The field-collected banana stem weevil, O. longicollis and banana corm weevil, $C$. sordidus were reared in the laboratory by providing fresh pseudostem and corm materials. Every 15 days, the weevils were separated from the existing rearing chamber and transferred into a new chamber. The rearing unit was placed in an insect rearing room with $23^{\circ} \pm 2{ }^{\circ} \mathrm{C}$ and $70 \%$ humidity. The male and female weevils were separated from culture prior to the experiment. Ten weevils from each species and sex were used per treatment. The treatments were as follows: T1, blue LED + LSBST; L2, LSBS/corm trap alone, and T3, LED alone. The experiment was replicated thrice, and weevil attraction was recorded and presented in percentage.

The mean number and percentage of LED-attracted insect pests in the banana garden were analysed by oneway ANOVA and pairwise comparison using Paleontological Statistics (PAST) software ${ }^{22}$. A $P$-value $<0.05$ was considered significant among or between treatments.

As a preliminary study, evaluation of LED traps was carried out at ICAR-National Research Centre for Banana (NRCB), Tiruchirappalli (District), Tamil Nadu, India,

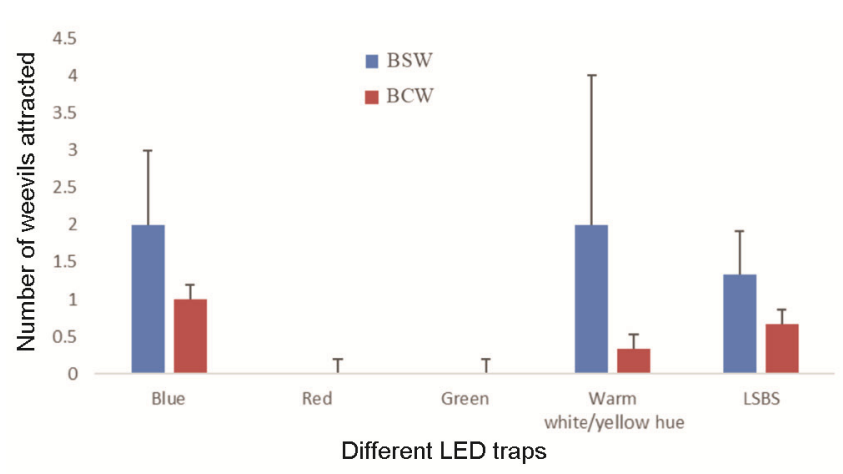

Figure 1. Attractiveness of LED light on monitoring weevils in the banana garden. T1, Blue + LSBST; T2, Red + LSBST; T3, Green + LSBST; T4, Warm white/yellow + LSBST, T5, LSBS trap alone.

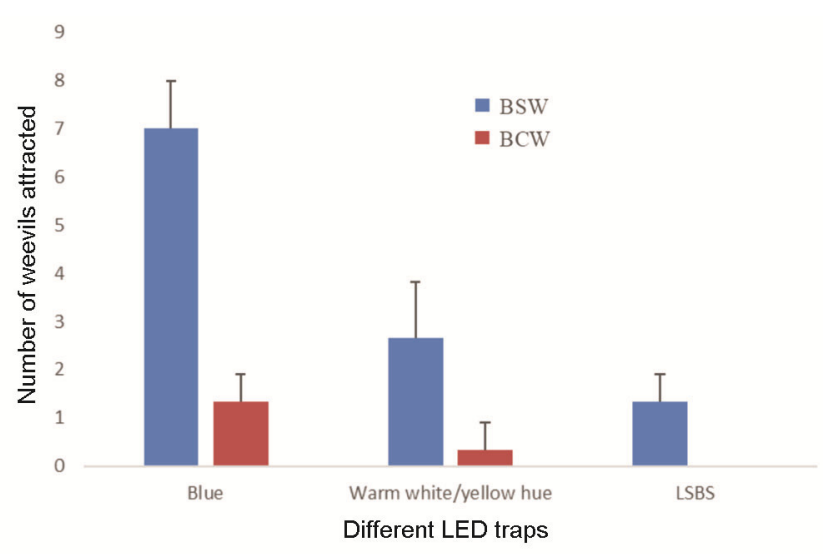

Figure 2. Attractiveness of blue and warm white/yellow LED light towards weevils in the banana garden. 


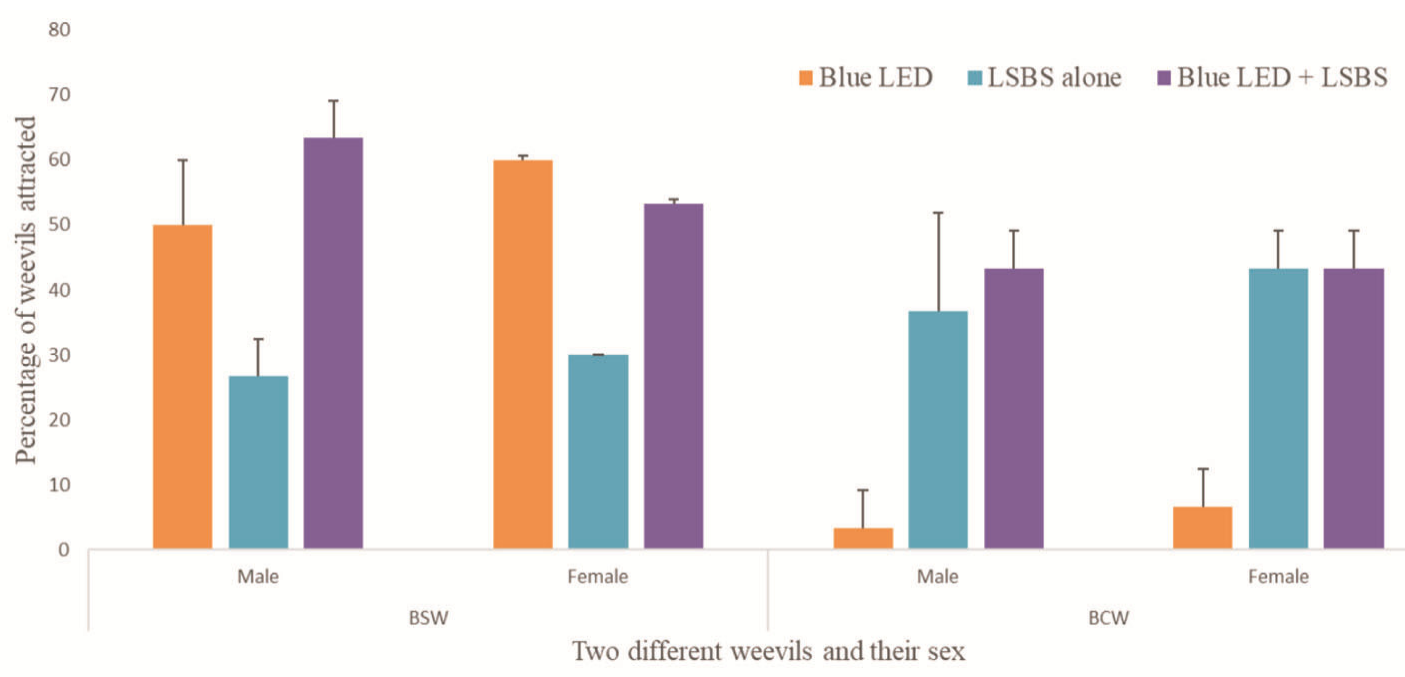

Figure 3. In vitro characterization of photoreception in banana weevils to the blue LED.

but less weevil trapping was recorded due to the low level of infestation. For this study, we selected banana gardens which were endemic to weevils. The pre-surveillance data indicated that the selected banana fields at Thirukkattupalli and Tiruppanandal showed $40 \%$ and $50 \%$ infestation for banana stem weevil respectively, and 30\% and $15 \%$ of infestation for corm weevil respectively. The infestation rate was calculated based on the overall infested banana plant in the field/acre. Field evaluation showed that the banana weevils were attracted to plant of LED lights. Among the four LEDs, blue and warm white/ yellow LEDs showed attraction of banana stem weevil close to significant value than other LEDs $(F=2.874$, $\mathrm{d} f=4, P=0.08)$. However, blue LEDs did not attract significant number of banana corm weevils $(F=1.699$, $\mathrm{d} f=2, P=0.2262$ ) (Figure 1 ). To confirm and evaluate the attractive efficacy of blue and yellow LED traps, they were again studied under field condition. The results revealed that significant difference was found among the traps (blue, yellow and pseudostem) for stem weevil $(F=29.63, \mathrm{~d} f=2, P=0.0008)$ and corm weevil $(F=6.5$, $\mathrm{d} f=2, P=0.0315)$. Interestingly, significant difference was recorded for stem/corm with blue LED when compared with LED alone, as analysed using one-way ANOVA-Tukey's pairwise comparison (Figure 2).

In addition to the field study, photoreception of banana weevils under controlled insect chamber towards blue LED alone, LSBS/corm trap alone, and LED + LSBS/ corm trap was studied. The results revealed that significant difference was found between the traps in both the weevils and for both sexes (banana stem weevil male: $F=18.6, \mathrm{~d} f=2, \quad P=0.0027$ and female: $F=17.11$, $\mathrm{d} f=2, P=0.003$; banana corm weevil male: $F=13.78$, $\mathrm{d} f=2, \quad P=0.005$ and female: $F=40.33, \mathrm{~d} f=2, \quad P=$ $0.0003)$. This experiment further confirmed that blue LED significantly attracted more weevil when it was eva- luated along with stem trap. The response of banana corm weevil was meagre to LED traps. But more weevil attractions were recorded with corm alone and LED with a corm trap. However, there was no significant difference between corm alone and LED with corm trap using oneway ANOVA-Tukey's pairwise comparison (Figure 3). This may be due to the negative phototactic behaviour of corm weevil. The use of blue LEDs could be economically safe and reduces the risk of electric shock to the operator as fluorescent tubes need high voltage.

The area under banana cultivation is increasing and is also affected by various pests ${ }^{2}$. $O$. longicollis and $C$. sordidus have been a major threat to banana cultivation ${ }^{4}$. Technologies for the management of banana weevils involving identification of resistant sources, monitoring and managing them using LSBS trap coated with Beauveria bassiana as a delivery system for biocontrol method and semiochemicals have been developed and practised by the farmers ${ }^{3,4,23-26}$. The use of light-based trap is the present trend and one of the best components in the Integrated Pest Management (IPM) programme. In the present study, attraction of a large number of $O$. longicollis to blue LED was found when compared with $C$. sordidus. Bae et al. ${ }^{13}$ and Park and Lee ${ }^{16}$ reported that blue LED is more attractive for a wide range of insect pests, including Coleoptera than UV LED, and green, yellow, white and infrared LEDs. The attraction of corm weevil blue LEDs was less when compared with other LEDs. However, blue LED enhanced the capture of banana stem weevil where used alone, but it reduced weevil attraction when implemented with other LEDs in the field (pers. obs.). This may be due to the phototaxis nature of other LEDs towards banana stem weevil which disturbed their movement towards blue LED.

Through the results of an in vitro study under controlled environment, we found that blue LED alone when 


\section{RESEARCH COMMUNICATIONS}

used in isolation attracted the weevils, but in 10 min they moved away. This demands a host to be in tandem with LED light in order to enhance the trapping efficiency. This is the reason that blue LED trap could not retain the attracted weevils in the field. This concept was supported by the study of McQuate et $a .^{20}$, who reported that green LED with pheromone trap caught a significant number of sweet potato weevils (Cylas formicarius). Similarly, a combination of olfactory and visual cues were efficiently used for capturing the cigarette beetle, Lasioderma serricorne but in the case of Cylas formicarius, attraction was recorded to green LED with pheromone trap ${ }^{18,19}$. It has been reported that red LED attracted the highest percentage of Tribolium castaneum adults under storage condition, but there was no response by the banana weevils, this could be due to species-specific variation in the photoreception $^{20}$.

Hori et al. $^{27}$ suggested that radiating blue light (LED) is a novel, clean and safe pest control technique by simply killing the insect pests. The LEDs + entomopathogenic fungus (Beauveria bassiana and Metarhizium anisopliae)-coated LSBST can be used as a biocontrol trap and an eco-friendly approach for weevil management ${ }^{27,28}$. Further research is required to fully understand the molecular mechanism of LED on the behaviour of on banana weevils and the effect of LED on eco-friendly insects. This method of trapping has advantages of being cheap and easily available, but also needs improvement in design, height of traps and wavelength of light emitted by them, and the effect of lunar phase on the $\operatorname{catch}^{24}$. In future, development of LEDs (specific to insects with the respective wavelength and colour) with chemicals based on either banana weevil pheromone or host plant volatiles could be an important component in IPM for the monitoring and control of banana weevils ${ }^{25,29}$.

The study shows that blue LED + LSBS trap can be used in the field for monitoring and mass-trapping of banana weevils. To the best of our knowledge, there are no previous reports of LED with LSBS trap as a method for the monitoring and management of banana weevils.

1. FAO, Banana market review: preliminary results-2019, Food and Agriculture Organization, Rome, 2020.

2. Padmanaban, B., Pests of banana. In Pests and their Management, Springer, Singapore, 2018, pp. 441-455.

3. Padmanaban, B., Kannan, M., Uma, S., Saraswathi, M. S., Backiyarani, S. and Ashif, K. K., Field evaluation and in vivo screening of Musa germplasm against banana stem weevil, Odoiporus longicollis. J. Entomol. Zool. Stud., 2020, 8, 290-296.

4. Padmanaban, B., Sundararaju, P., Velayudhan, K. C. and Sathiamoorthy, S., Evaluation of Musa germplasm against banana weevil borers. InfoMusa, 2001, 10, 26-28.

5. Féménia, F. and Letort, E., How to achieve significant reduction in pesticide use? An empirical evaluation of the impacts of pesticide taxation associated to a change in cropping practice (No. 233482), Institut National de la recherche Agronomique (INRA), Departement Sciences Sociales, Agriculture et Alimentation, Espace et Environnement (SAE2), 2016.
6. Sliney, D. H., Gilbert, D. W. and Lyon, T., Ultraviolet safety assessments of insect light traps. J. Occup. Environ. Hyg., 2016, $13,413-424$.

7. Green, D., MacKay, D. and Whalen, M., Next generation insect light traps: the use of LED light technology in sampling emerging aquatic macroinvertebrates. Aust. J. Entomol., 2012, 39, 189.

8. Kim, M. G., Yang, J. Y. and Lee, H. S., Phototactic behavior: repellent effects of cigarette beetle, Lasioderma serricorne (Coleoptera: Anobiidae), to light-emitting diodes. Korean Soc. Appl. Biol. Chem., 2013, 56, 331-333.

9. Chen, Y., Luo, C. W., Kuang, R. P., Li, H. W., Chen, Z. and Liu, Y. J., Phototactic behavior of the Armand pine bark weevil, Pissodes punctatus. J. Insect Sci., 2009, 13, 3.

10. Ishikura, S., Subsequent fluorescent light trap. J. Agric. Sci., 1950, 5, 15-19.

11. Ju, Q., Qu, M. J., Chen, J. F., Zhao, Z. Q., Niu, H. L., Zhou, Q. and $\mathrm{Yu}, \mathrm{S}$. L., The influence of spectral and sexual differences on phototaxis action of several kinds of beetles. Chin. J. Entomol., 2010, 47(3), 512-516.

12. Jaeger, R. G. and Hailman, J. P., Two types of phototactic behaviour in anuran amphibians. Nature, 1971, 230, 189-190.

13. Bae, S., Park, J. O., Mainali, B., Kim, H., Yoon, Y., Lee, Y. and Cho, Y., Evaluation of different light colors in solar trap as attractants to cereal and legume insect pests. Korean J. Environ. Agric., 2015, 27, 516-521.

14. Chen, Z., Kuang, R. P., Zhou, J. X. and Liu, X., Phototactic behaviour in Aphidius gifuensis (Hymenoptera: Braconidae). Biocontrol Sci. Technol., 2012, 22, 271-279.

15. Infusino, M., Brehm, G., Di Marco, C. and Scalercio, S., Assessing the efficiency of UV LEDs as light sources for sampling the diversity of macro-moths (Lepidoptera). Eur. J. Entomol., 2017, 114(114), 25-33.

16. Park, J. H. and Lee, H. S., Phototactic behavioral response of agricultural insects and stored-product insects to light-emitting diodes (LEDs). Appl. Biol. Chem., 2017, 60, 137-144.

17. Zheng, L. X., Zheng, Y., Wu, W. J. and Fu, Y. G., Field evaluation of different wavelengths light-emitting diodes as attractants for adult Aleurodicus dispersus Russell (Hemiptera: Aleyrodidae). Neotrop. Entomol., 2014, 43, 409-414.

18. Hironaka, M., Kamura, T., Osada, M., Sasaki, R., Shinoda, K., Hariyama, T. and Miyatake, T., Adults of Lasioderma serricorne and Stegobium paniceum (Anobiidae: Coleoptera) are attracted to ultraviolet (UV) over blue light LEDs. J. Econ. Entomol., 2017, 110, 1911-1915.

19. Miyatake, T. et al., Monitoring and detecting the cigarette beetle (Coleoptera: Anobiidae) using ultraviolet (LED) direct and reflected lights and/or pheromone traps in a laboratory and a storehouse. J. Econ. Entomol., 2016, 109, 2551-2560.

20. McQuate, G. T., Green light synergistally enhances male sweetpotato weevil response to sex pheromone. Sci. Rep., 2014, 4, 4499.

21. Guo, L. et al., Large reductions in pesticides made possible by use of an insect-trapping lamp: a case study in a winter wheat-summer maize rotation system. Pest Manage. Sci., 2018, 74, 1728-1735.

22. Hammer, Ø., Harper, D. A. and Ryan, P. D., PAST: Paleontological statistics software package for education and data analysis. Palaeontol. Electron., 2001, 4, 9.

23. Palanichamy, S., Padmanaban, B., Vaganan, M. M. and Uma, S., Electrophysiological and behavioural responses of banana pseudostem weevil, Odoiporus longicollis Olivier (Coleoptera: Curculionidae) to aggregation pheromone, 2-methyl-4-heptanol and host plant kairomones. Curr. Sci., 2019, 116, 1753.

24. Padmanaban, B., Thangavelu, R., Gopi, M. and Mustaffa, M. M., Effect of mass multiplication media on sporulation, field efficacy and shelf life of Beauveria bassiana against rhizome and pseudostem weevils of banana. J. Biol. Control, 2009, 23, 277-283.

25. Alagesan, A., Padmanaban, B., Tharani, G., Jawahar, S. and Manivannan, S., An assessment of biological control of the banana 
pseudostem weevil Odoiporus longicollis (Olivier) by entomopathogenic fungi Beauveria bassiana. Biocatal. Agric. Biotechnol., 2019, 20, 101262

26. Alagesan, A., Tharani, G., Padmanaban, B., Sivaramakrishnan, S. and Manivannan, S., Kairomones from highly susceptible host to control banana pseudostem weevil, Odoiporus longicollis (Olivier). Biocatal. Agric. Biotechnol., 2018, 16, 655-662.

27. Hori, M., Shibuya, K., Sato, M. and Saito, Y., Lethal effects of short-wavelength visible light on insects. Sci. Rep., 2014, 4, 7383.

28. Song, J., Jeong, E. Y. and Lee, H. S., Phototactic behavior 9: phototactic behavioral response of Tribolium castaneum (Herbst) to light-emitting diodes of seven different wavelengths. J. Appl. Biol. Chem., 2016, 59, 99-102.

29. Gaglio, G. et al., Effect of night time-intervals, height of traps and lunar phases on sand fly collection in a highly endemic area for canine leishmaniasis. Acta Trop., 2014, 133, 73-77.

ACKNOWLEDGEMENTS. We thank the Director, ICAR-National Research Centre for Banana, Tiruchirappalli and Dr S. Shantkriti, Kalasalingam Academy of Research and Education, Krishnankoil for support and valuable suggestions respectively. M.K. thanks SERB, DST for National Post-Doctoral Fellowship (PDF/2017/000316).

Received 10 June 2020; revised accepted 21 September 2020

\title{
Impact of urbanization on seasonal population status and occupancy of house sparrows in Delhi, India
}

\author{
Shikha Choudhary ${ }^{1, *}$, N. P. S. Chauhan ${ }^{1}$ and \\ Rajiv Kalsi ${ }^{2}$ \\ ${ }^{1}$ Amity Institute of Forestry and Wildlife, Amity University, \\ Noida 201 301, India \\ ${ }^{2}$ Department of Zoology, Mukand Lal National College, \\ Yamuna Nagar 135 001, India
}

Urbanization has a direct impact on avian communities as it modifies the landscape, consequently changing bird distribution, abundance and the resources on which avian populations depend. With increasing anthropocentric activities, there has been a marked decline in the urban population of house sparrows in Delhi, India. This study was undertaken to determine the impact of varying levels of urbanization (high-, medium- and low-density urban areas, suburban areas and agricultural areas) on the population and occupancy of sparrows. The encounter rate and occupancy probability were high in sub-urban and high-density urban areas, while they were low in low-

*For correspondence. (e-mail: shikhachoudhary03@gmail.com)

density urban and agricultural areas. With active public participation, the sparrows can be conserved and their population can be re-established in areas where they have become extinct.

Keywords: Encounter rate, house sparrow, occupancy, population status, urbanization.

As a landscape becomes more urbanized and anthropocentric, ecological conditions change rapidly and ultimately influence the distribution and population status of urban birds. Avian population density often increases, but species diversity tends to decrease ${ }^{1,2}$. Urbanization has direct and indirect effects on the native bird population, as town planning can change habitat, food availability, nest site availability, predator diversity, competitors and disease. These factors significantly affect the population structure and composition of urban birds ${ }^{3}$. As a result the most common and abundant bird species have become rare. The house sparrow (Passer domesticus) is one such urban bird that has suffered extensively due to urbanization $^{4,5}$.

The house sparrow is a member of family Passeridae which naturally occurs in Europe, parts of Asia and the Indian subcontinent. From these regions it has been introduced by humans, intentionally or accidentally, to the rest of the world ${ }^{6}$. The bird had a robust association with human civilization since the Bronze $\mathrm{Age}^{7}$, and has always been a crucial part of our culture and traditions. Across the world, the house sparrow is the most familiar bird and because of this familiarity, it is portrayed as the main character in many of our folklore, fables, ceremonial songs, stories, poems, idioms and phrases ${ }^{4,8}$. House sparrows serve as an important bioindicator species in urban landscapes ${ }^{9}$, and also have ecological services as they feed on insects from their surroundings and play a role in eliminating harmful insects like mosquito larvae.

A species once considered as a pest to crops and having a negative influence on native avifauna and human ${ }^{10}$, is now on the verge of extinction in urban landscapes across the globe. It is presently a 'Least concern' species in the IUCN Red List ${ }^{11}$. However, in recent decades a marked decline in the sparrow population has been reported in many cities around the world ${ }^{4-6,9,12}$. Since the mid-1970s, sparrow populations in rural areas have declined by $47 \%$, while a $60 \%$ reduction in urban sparrow populations has been reported ${ }^{12}$. Most population surveys conducted in different urban centres across India show a declining trend ${ }^{9,13-18}$. According to a survey report of Indian Council of Agricultural Research, house sparrow population had declined by $80 \%$ in Andhra Pradesh, 20\% in Kerala, Gujarat and Rajasthan and around $70-80 \%$ in the coastal areas ${ }^{4}$. According to the state of India Bird report $^{19}$, six largest metro cities (including Delhi) in the country witnessed a gradual decline in sparrow abundance. 